well be renal in origin. These renal changes are brought about by the trueta shunt, initiated by uterine distention and mediated by the utero-renal reflex. The renal ischaemia causes both the hypertension and the biochemical changes found in toxaemia.

While forcibly distending the horn of a rabbit's uterus may provoke diversion of its renal flow it is not permissible to argue from this that twins, primigravidae, accidental haemorrhage or hydramnios can cause a similar disturbance. In actual' fact on this premise acute hydramnios should cause marked and inevitable toxaemia, but this is not so.

The evidence of the biochemist, deduced from renal function tests, is also not in favour of there being any diminution in cortical blood flow, but the author overrides this by stating 'the biochemist cannot in all seriousness claim that his methods are a meticulous index of renal physiological and pathological mechanisms.'

Eclampsia itself is not explained specifically in relation to the utero-renal reflex, but Macintosh's recent suggestion in relation to the abnormal electroencephalogram pattern found in these cases receives the author's support.

The chapter on anuria stands in marked contrast to the rest of the book. Here the trueta mechanism is critically studied both in relation to cortical necrosis and to tubular necrosis. The apparently contrary evidence of Bull and his workers concerning renal flow in anuria is discussed. The treatment advised is also sound, although critical analysis of O'Sullivan's and Spitzer's cases treated by paravertebral block reveal results not quite so satisfactory as the author suggests.

Most of the book is unfortunately written in a style which tends to be both ponderous and complex, although the author's insistence on the importance of the Oxford shunt in toxaemia emerges clearly enough. It must regretfully be doubted whether this book will live up to its publisher's claim to be ' the most important contribution yet made in the study of a difficult problem.'

$$
\text { D.W.S.G. }
$$

\section{CLINICAL CARDIOLOGY}

Edited by Franklin C. Massey, M.D. Pp. xiv + I, IOO, with 250 illustrations. London: Baillière, Tindall \& Cox. 1953. I02s. $6 \mathrm{~d}$.

This book comprises 28 chapters, the majority of which are written by different authors. The first roo pages or so are devoted to anatomy, physiology and the findings in the normal heart, followed by an unhelpful chapter on 'Cardiac Evaluation by Physical Diagnosis.' There is much that is redundant in this part of the book, though it contains a useful chapter on ' The Heart in Childhood.' The following section on roentgenology is good but is illustrated only by line drawings. Electrocardiography is dealt with fully, particularly in regard to theory and to myocardial infarction. It seems a pity, however, that in a modern textbook of cardiology all the chest leads illustrated should not 3 be $\mathrm{V}$ leads rather than $\mathrm{CR}$ and even CF.

Bailey, Glover and O'Neill contribute the chapter. on surgery. Though this contains much of value and $\vec{F}$ interest it is the longest in the book and is perhaps $\stackrel{?}{?}$ too long even in these days for a medical textbook. The remaining clinical subjects are dealt with on an흘 aetiological basis; rheumatic, hypertensive, syphylitic, coronary and pulmonary heart disease. Most of these chapters might well have been condensed; there is repetition and sometimes contradiction, $\infty$ 'rheumatic pericarditis results in constrictive peri- $\overrightarrow{0}$ carditis '- rheumatic lesions never result in chronic constrictive pericarditis.' The inclusion of $\vec{\omega}$ certain congenital heart lesions (Fallot's tetralogy and septal defects) in the section on pulmonaryo heart disease is, to say the least of it, somewhat 3 . unorthodox.

The most serious fault in this book is the difficulty. or impossibility of obtaining adequate information $A$ on particular lesions. Thus on looking up mitral stenosis in the index one is referred to five different $\vec{N}$ chapters, and at the end of a long search the information is far from complete. Nowhere is there a full account of the physical signs of this important? disease.

It is difficult to say to whom this work would appeal; for those who have already some special? knowledge of cardiology there is much that is ro- $\overrightarrow{0}$ dundant, and for those who have not, there giss insufficient sound clinical description and too muen. technical detail.

$$
\text { G.T.T. } \stackrel{\oplus}{\rightleftharpoons}
$$

\section{SURGERY OF REPAIR AS APPLIED TO HAND INJURIES}

By B. K. BANK, M.S., F.R.C.S., F.R.A.C.S., and A. R. WAKEFIELD, M.S., F.R.C.S., F.R.A.C.S. Pp. xiv +256 , with 188 illustrations. Edin burgh: E. \& S. Livingstone, Ltd. 1953. 40s.

Success in the management of hand injuries calls for balanced judgment, technical precision ando meticulous after care; attributes of experience? which is often hard won and lengthy in acquisition. For, although there is an increasing growth of 3 special centres for these cases, much of this im-o portant work has, of necessity, to be undertaken? elsewhere. Bank and Wakefield, in writing on the basis of their own vast experience, have produced an excellent book which should be of value to all re- $\tilde{N}$ sponsible for the care of the injured hand.

In disclaiming any pretence to an exhaustive treatise and by the avoidance of lengthy dissertation on controversial issues, the authors are at once lucid $\omega$ and, above all, practical. This practical approach is evident throughout the book from the instructive section on examination of the injured hand, a model of careful appraisal, to the details of after care and rehabilitation. The problem of choice of procedure? where alternatives exist is always difficult but there? is much valuable guidance in forming these de 
cisions, particularly vital in gross hand injuries. By constantly regarding the hand as a composite functioning unit, the optimum ultimate result may be achieved for in the author's words: 'Hand surgery must not be fragmented into separate systems.'

Only too often extensor tendon injuries are considered to present no difficulty in repair with the aim of a good or even excellent result easily achieved and this in spite of the indifferent results frequently following the commonest extensor lesion, the mallet finger. In drawing attention to the peculiar and largely anatomical problems attending these injuries Bank and Wakefield aim at a degree of perfection which exemplifies the high standard they set in the treatment of all hand injuries.

Sections of particular interest in a well-planned work are those on the surgical anatomy of the hand and the special aspects of burns and injuries in children. The book is profusely illustrated by photographs and line drawings and well-produced. by the publishers.

\section{TEXTBOOK OF GENETICS}

By William Hovanitz, Ph.D. Pp. $x+419$, with 267 illustrations. London: Elsevier Publishing Co., Ltd. Distributors Cleaver-Hume Press. 1953. 42s. 6d.

The scope of Professor Hovanitz's book is considerable and it is probable that some of its less satisfactory features are due to the endeavour to compress too much information into too few pages. A short preface reminds the reader of what he should know and may have forgotten and also gives a summary of the author's philosophical approach to genetics. In common with the rest of the book, and with a greater frequency, the preface is marred by what appear to be printer's errors and also by examples of almost meaningless phraseology. For the most part, however, the book is clearly written. Excellent introductory chapters deal with Mendelism and explain the mathematics of probability, but the manner of presentation of some later chapters is less happy. For instance the statement is made that achondroplasia is a simple inherited condition which usually appears as a dominant; this statement is accompanied by a pedigree in which the symbols are unexplained, but whatever interpretation one gives to them the pedigree does not appear to illustrate the behaviour of a dominant. Similarly the references to the inheritance of comb-structure of the fowl, although undoubtedly quite clear to a practiced geneticist would be difficult for a student or non-specialist to understand because they contain words used in an inexact manner. The sections dealing with plant genetics are accompanied by an excellent account of gametogenesis and embryogenesis of plants - an account that many writers of botanical textbooks might well study. The chromosome is described very clearly both from the cytological and cytochemical aspects. Most of the remainder of the book deals with complicated genetical phenomena, some of which, notably the shell-coiling of snails, are dismissed so concisely as to be incomprehensible. In this example matters are not improved by a textual error that has introduced a new and unexplained gene. Modern studies of the genetics of bacteria are scarcely touched on; viruses are not mentioned.

At intervals the book contains unanswered questions designed to arouse curiosity and the desire to investigate. Surely no one but a serious student would be reading this work and he would be better helped by questions to which he could check his answer. The omission of adequate references to work cited is a grave fault and should be rectified in any subsequent edition. In general, however, the book is stimulating and informative and provides a useful addition to the literature of the subject. A.F.

\section{M.R.C. Special Report Series, No. 280 VITAMIN C REQUIREMENT OF HUMAN ADULTS}

A Report by the Vitamin C Sub-Committee of the Accessory Food Factors Committee

Compiled-by W. Bartley, H. A. Krebs and J. R. P. O'Brien. Pp. viii + I79, with 24 illustrations, 6 in colour. London: H.M.S.O. 1953. 17s. 6d.

This publication contains the detailed aspects of the vitamin $\mathbf{C}$ deprivation experiment carried out on human volunteers towards the end of the war. A brief report of the main findings appeared in The Lancet in 1948. A detailed index is lacking but the subdivision into three main sections allows easy reference to the many clinical, biochemical and metabolic aspects of vitamin $\mathbf{C}$ deficiency that have been covered. Many of the earlier problems of the diagnosis of scurvy have been overcome by diligent observation which forms a striking characteristic in this brilliant experiment. The relative inadequacy of biochemical methods as compared with clinical observation in the diagnosis of early scurvy is well illustrated and previous reports that wound healing becomes delayed only after the appearance of clinical scurvy are confirmed. In the achievement of its primary object, however, the report is outstanding in that it presents convincing evidence that the minimum daily requirement of vitamin $C$ for the prevention of scurvy in healthy adults not undertaking strenuous physical work is in the region of only ro mg.

To those with special interests in vitamin C metabolism criticism could only be levelled in that the publication was not more detailed in certain aspects. The comparatively large section devoted to follicular hyperkeratosis stresses the importance of this physical sign as a simple diagnostic tool but little mention is made of its characteristic distribution and the possible influence, as seen in this survey, that clothing or other external agents may have in this regard. Those with experience of clinical scurvy will note that the stage of extensive ecchymoses and intramuscular haematomata was not reached in this study and may feel that this 